\title{
Correction to: Photocatalytic hydrogen production on chemically etched strontium titanate surfaces
}

\author{
Burcu Oral $^{1}$ (D) Dilara Saadetnejad ${ }^{1}$ (D) $\cdot$ Ramazan Yıldırım $^{1}$ (D)
}

Published online: 25 October 2021

(c) Akadémiai Kiadó, Budapest, Hungary 2021

\section{Correction to: Reaction Kinetics, Mechanisms and Catalysis (2020) 131:953-963 https://doi.org/10.1007/s11144-020-01872-y}

In the original publication of the article a systematic error was noticed in Gas Chromatograpy calibration for $\mathrm{H}_{2}$. Hydrogen production rates in Figs. 4-6 and related discussions should be divided by 100 for the true values.

Publisher's Note Springer Nature remains neutral with regard to jurisdictional claims in published maps and institutional affiliations.

The original article can be found online at https://doi.org/10.1007/s11144-020-01872-y.

\section{Ramazan Yıldırım}

yildirra@boun.edu.tr

1 Department of Chemical Engineering, Boğaziçi University, İstanbul, Turkey 